\title{
Influence of Solution Annealing on Microstructure and Mechanical Properties of Maraging 300 Steel
}

\author{
Venceslau Xavier Lima Filho ${ }^{a *}$, Isabel Ferreira Barros ${ }^{a}$, Hamilton Ferreira Gomes de Abreu ${ }^{a}$ \\ ${ }^{a}$ Laboratory of Materials Caracterization, Physical Metallurgy and Phase Transformation Research \\ Group, Department of Metalurgy Engineering and Materials, Federal University of Ceará - UFC, \\ Fortaleza, CE, Brazil
}

Received: March 29, 2016; Revised: August 27, 2016; Accepted: October 20, 2016

\begin{abstract}
Maraging 300 belongs to a family of metallic materials with extremely high mechanical strength and good toughness. Some works have been published about aging temperatures that improve ultimate strength resistance with acceptable toughness levels in this steel family, where the prior austenite grain size obtained by different solution annealing temperature influence in the final mechanical properties. Solution annealing temperatures ranging from $860^{\circ} \mathrm{C}$ to $1150{ }^{\circ} \mathrm{C}$ and were kept constant until the aging temperature. These treatments were used in order to investigate their influence on the microstructure and mechanical properties of maraging steel 300 , especially with regard to toughness. The characterization of the microstructure was performed by optical microscopy, scanning electron microscope (SEM) and X-ray diffraction (XRD). Mechanical properties were evaluated by Rockwell $\mathrm{C}$ hardness and Charpy impact tests. The results showed that there is a temperature range where one can get some improvement in toughness without a large loss of mechanical strength.
\end{abstract}

Keywords: maraging 300, heat treatment, microstructure, toughness

\section{Introduction}

Maraging steels are a family of metallic materials with extremely high mechanical strength and good toughness ${ }^{1}$. The maraging steels have excellent formability in the solution annealed state and a great ability to harden by aging ${ }^{2}$. Any cooling rate leads to the formation of a martensitic structure BCC only in the solubilization treatment, however, may occur reversal of austenitic phase at high temperatures aging treatment. This martensite is ductile and reasonably cold workable consequence of the low-carbon and high nickel content in their chemical composition. According to Sinha et al. ${ }^{3}$, grain growth in maraging steel is very complex due to the influence of the alloying elements present, which in turn, interact differently with grain boundaries. Another factor that can explain this event is the precipitation of TiC and $\operatorname{Ti}(\mathrm{CN})^{3-6}$.

Literature also shows that maraging steel increases mechanical strength when subjected to aging heat treatments in the range $440{ }^{\circ} \mathrm{C}$ to $650^{\circ} \mathrm{C}$, depending on the properties that are desired to reach ${ }^{7}$. This heat treatment, in turn, in addition to harden the material, particularly at temperatures above $450^{\circ} \mathrm{C}$ may lead to precipitation of some phases, such as $\mathrm{Ni}_{3}(\mathrm{Mo}, \mathrm{Ti}), \mathrm{Fe}_{2} \mathrm{Mo}^{8}$.

This study aims to evaluate different solution annealing temperatures, how they influence grain size, toughness and ultimate strength after final aging.

\section{Material and Methods}

A maraging 300 steel round bar produced by vacuum induction melting process (VIM) followed by vacuum arc refining process (VAR), hot forged and solution annealed at $860^{\circ} \mathrm{C}$ (for 10 hours to complete homogenization of the ingot) was used for this experiment. The chemical composition of the steel is presented in Table 1. The steel bar was cold-rolled and cut to produce samples for the different tests performed.

Samples were solution annealed at $860,900,950,1000$, 1050,1100 e $1150^{\circ} \mathrm{C}$ for one hour. Part of samples were aged at $480^{\circ} \mathrm{C}$ for 3 hours to achieve peak hardness 9 . Many studies suggest the use of solution annealed heat treatments at $820^{\circ} \mathrm{C}$ and aging at $480^{\circ} \mathrm{C}$ as been the ideal for maraging 300 steel. This condition was exaustly tested with results published on the literatura and were used in this study for comparison referencial ${ }^{1,3,9}$.

Samples were quenched in water after each heat treatments to suppress the thermal embrittlement phenomena, which is normally observed in maraging steels after exposure to temperatures above $1100{ }^{\circ} \mathrm{C}$, as reported in previous examination $^{10}$.

Table 2 presents a summary of the heat treatments performed.

Microstructural characterization of samples was performed with a standard metallographic procedure and then etched with ammonium persulfate to reveal microstructure and $2 \%$ Nital to reveal the grain boundaries. Microstructural characterization was carried out using a Scanning Electron Microscope FEI XL30. The evaluation of the average grain 
Table 1: Chemical composition of Maraging 300 steel (wt \%).

\begin{tabular}{lccccccc}
\hline $\mathrm{Ni}$ & $\mathrm{Mo}$ & $\mathrm{Co}$ & $\mathrm{Ti}$ & $\mathrm{Al}$ & $\mathrm{C}$ & $\mathrm{Mn}$ & $\mathrm{Si}$ \\
\hline 18.4 & 5.04 & 9.35 & 0.76 & 0.1 & 0.01 & 0.02 & 0.05
\end{tabular}

Table 2: Summary of heat treatments.

\begin{tabular}{ccc}
\hline Samples & $\begin{array}{c}\text { Annealing temperature } \\
(1 \mathrm{~h})\end{array}$ & $\begin{array}{c}\text { Aging temperature } \\
(3 \mathrm{~h})\end{array}$ \\
\hline & $860^{\circ} \mathrm{C}$ & \\
& $900^{\circ} \mathrm{C}$ \\
& $950^{\circ} \mathrm{C}$ & - \\
Group S & $1000^{\circ} \mathrm{C}$ & \\
& $1050^{\circ} \mathrm{C}$ & \\
& $1100^{\circ} \mathrm{C}$ \\
& $1150^{\circ} \mathrm{C}$ \\
\hline & $860{ }^{\circ} \mathrm{C}$ \\
& $900^{\circ} \mathrm{C}$ \\
& $950{ }^{\circ} \mathrm{C}$ \\
& $1000^{\circ} \mathrm{C}$ & \\
& $1050^{\circ} \mathrm{C}$ & \\
& $1100^{\circ} \mathrm{C}$ & \\
& $1150^{\circ} \mathrm{C}$ & \\
\hline
\end{tabular}

size was performed by measuring the diameter of equivalent area with individual grains, according to the intercept method by ASTM E112 using Image-Pro software on a Microscope Olympus Optical BX51M.

The X-ray diffraction was used to characterize the phases present and was performed in a PANalytical X-Pert.-Pro diffractometer. The parameters to be measured were: copper tube monochromator scan range angles between 35 and 95 ${ }^{\circ}$ with steps of $0.02^{\circ}$ step time of $2.5 \mathrm{sec}$ and scan speed of $0.008 \%$ s. Rockwell $\mathrm{C}$ hardness and Charpy tests (with subsize dimensions of $7,5 \times 10 \times 55 \mathrm{~mm}$ ) were performed in accordance with the respective ASTM standards.

\section{Results}

\subsection{Microstructure}

Microstructural analysis of the Maraging 300 samples in the received condition, revealed a microstructure mainly composed of martensite, as can be seen in Figure 1. The average size of prior austenite grains was $6 \mu \mathrm{m}$.

The X-ray diffraction analysis presented in Figure 2 shows that the solution annealed and aged samples are essentially composed by the cubic phase martensite $(\alpha)$ which is characteristic of maraging steel.

\subsection{Grain Growth}

Optical microscopy of annealed samples revealed essentially uniform and equiaxed microstructure of prior

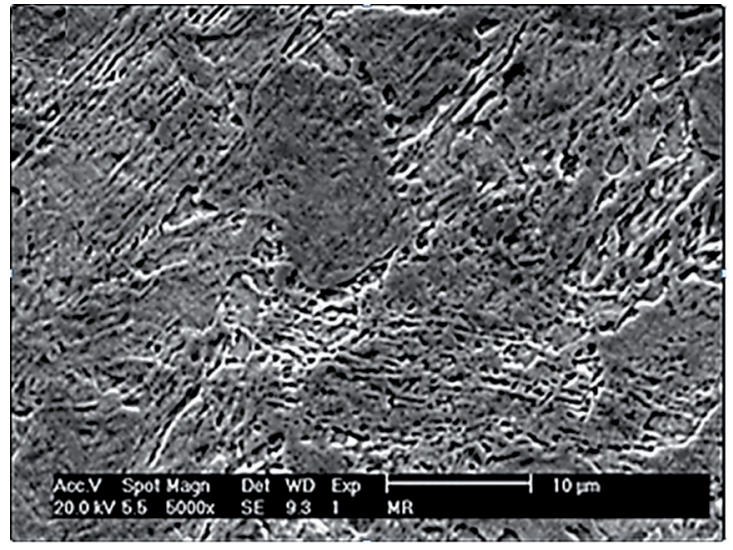

Figure 1: Maraging 300 in the "as received" condition. SEM image with 5000x magnification.

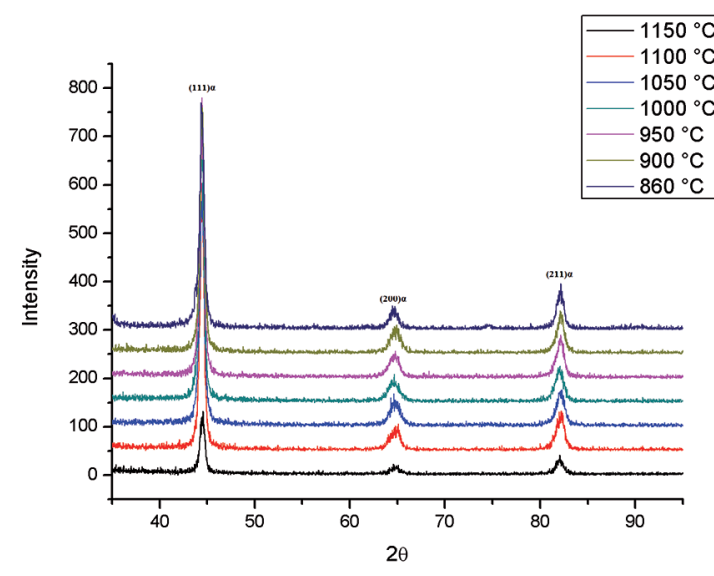

Figure 2: X-ray Diffraction patterns for samples annealed at various temperatures and aged at $480{ }^{\circ} \mathrm{C}$.

austenite grains, without abnormal grain growth. Figure 3 (a-g) shows typical micrographs of samples annealed at temperatures of 860, 900, 950, 1000, 1050, 1100 and 1150 ${ }^{\circ} \mathrm{C}$ for 1 hour, where can be observed an increase in the size of the prior austenite grains with the heat treatment temperature.

The curve of prior austenite grain size versus annealing temperature (Figure 4) indicates that the recrystallization finished before $860{ }^{\circ} \mathrm{C}$ and clearly shows that the growth rate is relatively slow between 860 and $1000{ }^{\circ} \mathrm{C}$ and quickly rises above $1150{ }^{\circ} \mathrm{C}$, with values ranging approximately $8 \mu \mathrm{m}$ at $860{ }^{\circ} \mathrm{C}$ to $164 \mu \mathrm{m}$ for the sample annealed at $1150{ }^{\circ} \mathrm{C}$. Other literatures about $18 \mathrm{Ni}$ maraging steels revealed that the prior autenite grain reached close to $140 \mu \mathrm{m}$ in ref. ${ }^{11}$ and $190 \mu \mathrm{m}$ in ref. ${ }^{1}$ at the same conditions.

Measurement of the grain size for the annealed and aged samples revealed that there was small variation than those which were only annealed. It was observed that the grain size for the sample annealed at $860{ }^{\circ} \mathrm{C}$ followed by aging is $6 \mu \mathrm{m}$ and for the sample annealed at $1150{ }^{\circ} \mathrm{C}$ followed by the same aging process is $198 \mu \mathrm{m}$. 


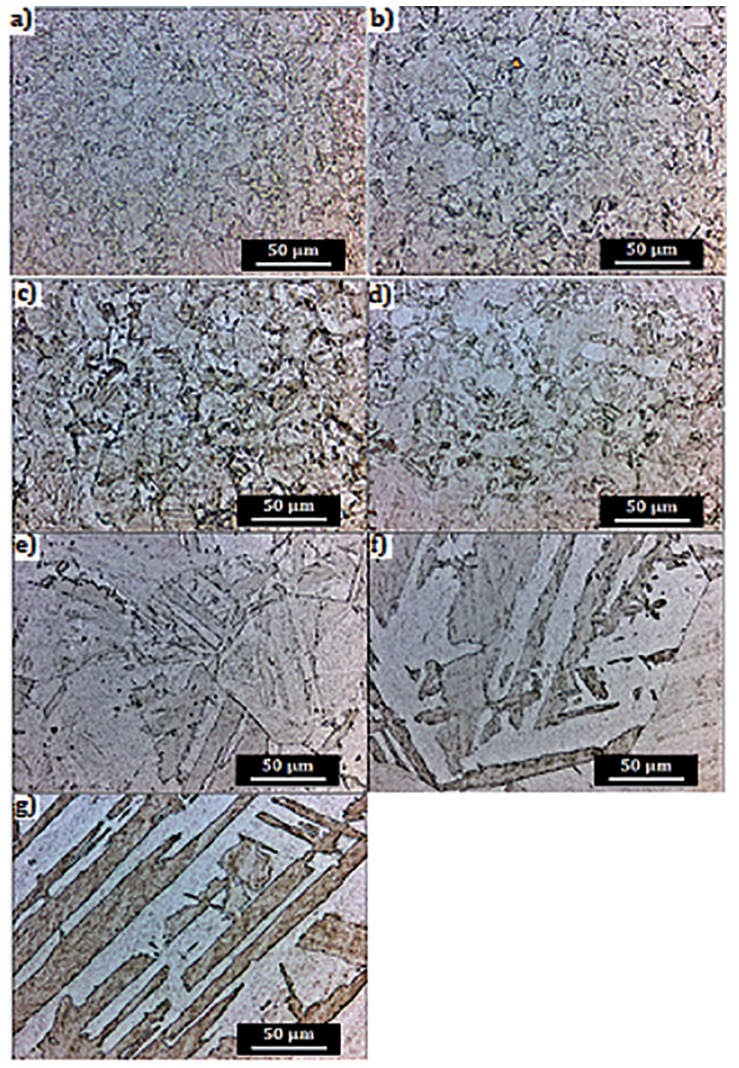

Figure 3: Microstructure of samples solution annealed for 1 hour at a) $860{ }^{\circ} \mathrm{C}$, b) $900{ }^{\circ} \mathrm{C}$, c) $950{ }^{\circ} \mathrm{C}$, d) $1000^{\circ} \mathrm{C}$, e) $1050{ }^{\circ} \mathrm{C}$ f) 1100 ${ }^{\circ} \mathrm{C}$ g) $1150{ }^{\circ} \mathrm{C}$. Magnification 500x.

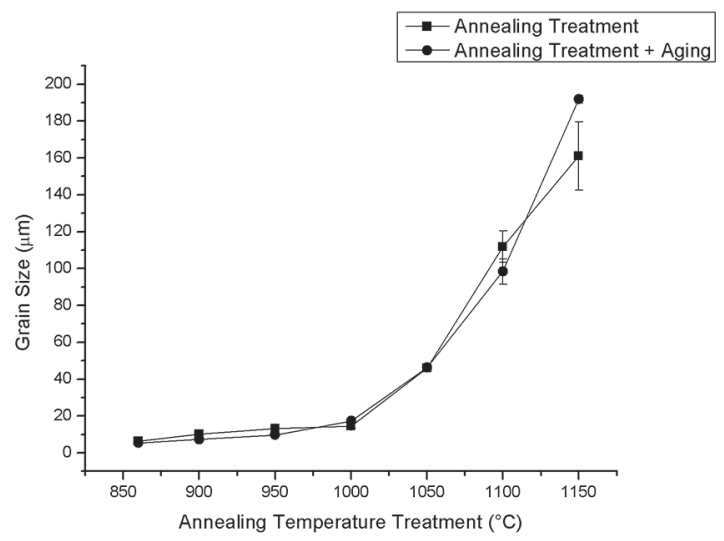

Figure 4: Prior austenite grain size for different annealing temperatures.

\subsection{Hardness}

The effect of annealing and aging on the hardness in the Maraging samples is shown in Figure 5. We can see that the hardness values for annealing and aged samples are almost double the values for samples subjected only to the solution treatment and that despite the average value of annealing samples in $1000^{\circ} \mathrm{C}$ and aged to show slightly higher than the other, we cannot say that the annealing temperature caused significant changes in hardness values.

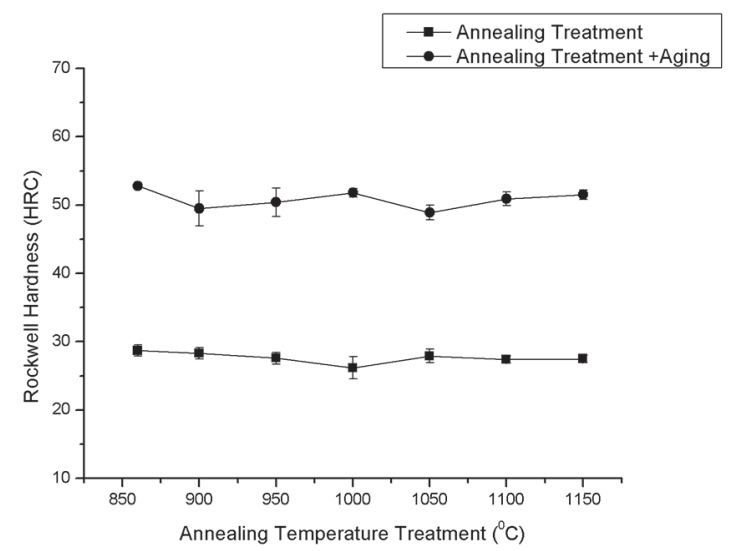

Figure 5: Results of the Rockwell Hardness tests of the solution treatment samples and solution treatment + aging samples.

\subsection{Toughness}

The effects of the aging and solution annealing on the toughness can be observed by the results of Charpy impact test, of which values are shown in Figure 6. The results show an increase trend of Charpy energy for temperatures between 860 and $1000{ }^{\circ} \mathrm{C}$ where upon this temperature tend to fall back to reverse. The material in the condition as received, without aging heat treatment, presented absorbed energy of $48 \mathrm{~J}$ in the Charpy impact test. The best result for aged samples was $23 \mathrm{~J}$ for the sample solution annealed at $1000{ }^{\circ} \mathrm{C}$ and aged for 3 hours at $480{ }^{\circ} \mathrm{C}$.

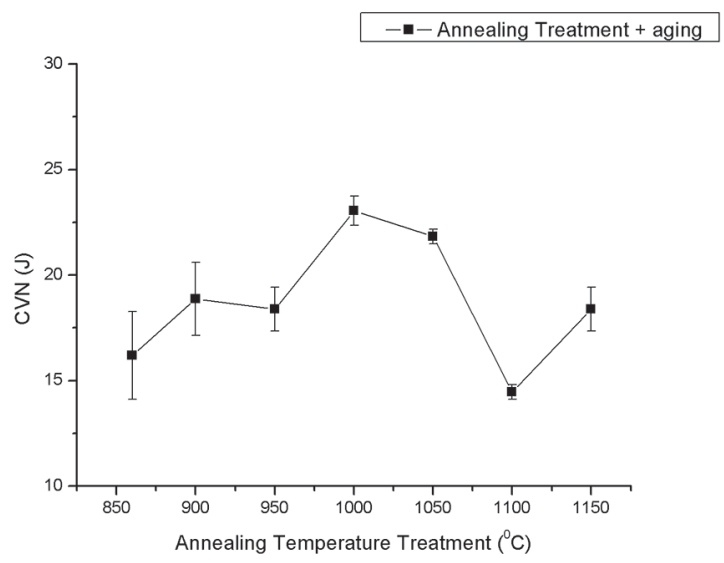

Figure 6: Charpy impact energy for samples solution annealed and aged at $480^{\circ} \mathrm{C}$.

\subsection{Fractography}

The fractographic analysis of cross section of the Charpy test samples, made by scanning electron microscopy indicated that this fracture mode in all conditions, was ductile with the formation of microvoids and spread transgranular by coalescence, as can be seen in Figure 7. 


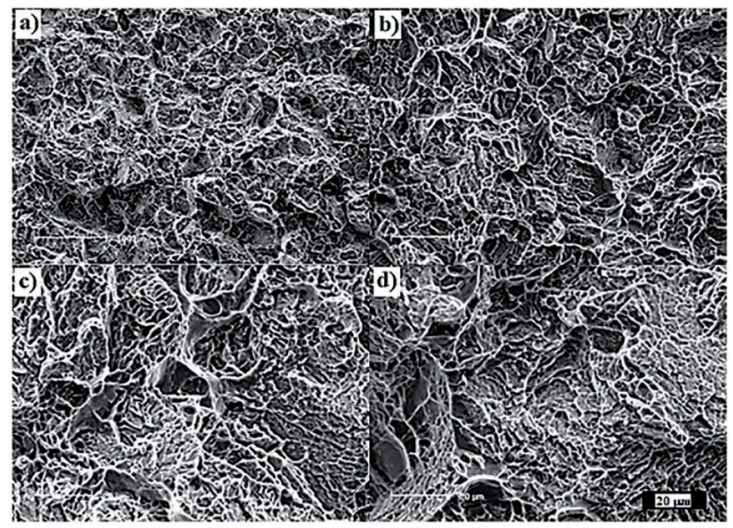

Figure 7: Cross section of test specimens after the Charpy test presenting ductile fracture for annealing and aged samples. Annealing temperature in ${ }^{\circ} \mathrm{C}$ (Charpy absorbed energy in J) a) $950{ }^{\circ} \mathrm{C}(18,39 \mathrm{~J})$; b) $1000{ }^{\circ} \mathrm{C}(23,05 \mathrm{~J})$; c) $1050{ }^{\circ} \mathrm{C}(21,83 \mathrm{~J})$, d) $1100^{\circ} \mathrm{C}(14,87 \mathrm{~J})$. The Charpy toughness tests were performed with subsize specimens with cross section $7,5 \times 10 \mathrm{~mm}$.

\section{Discussion}

It is well established that when austenite is heated to higher temperatures or held for a long time annealing the grain size increases. The surface tension force is responsible for this grain growth. It is also expected that the grain growth of austenite result in martensite with lower ultimate strength and toughness ${ }^{12}$. While for most cases this phenomenon occurs, in the maraging steel used in this work even with the increase of the grain size was observed increased toughness of the material, particularly when compared the results of solution annealed samples between $860^{\circ} \mathrm{C}$ and $1000^{\circ} \mathrm{C}$ and aged at $480{ }^{\circ} \mathrm{C}$. Only after the heat treatments performed above $1050{ }^{\circ} \mathrm{C}$ was possible to conclude that increased grain caused that reduction on the Charpy energy. In this study it was not observed a sharp decrease in the ultimate strength of this alloy.

Similar behavior was observed by $\mathrm{He}$ et al. ${ }^{13}$ in a maraging steel without cobalt. They concluded that in samples only solution annealed the tensile strength and toughness were not influenced by grain size. According to them, in this condition there was no change in the martensite spacing or dislocation tangles. Already in the aged samples it was also found that after $1100{ }^{\circ} \mathrm{C}$ both the tensile strength and the toughness suffered a sharp decline. Studies are being continued to have an explanation for this fact. It is known that increasing the solution temperature responsible for the increase of grain size increases the martensite transformation temperature. The martensitic transformation samples treated above $1100{ }^{\circ} \mathrm{C}$ resulted, in the case of maraging without cobalt, in a severe precipitation of $\mathrm{Ni}_{3} \mathrm{Ti}$ in the grain boundary of the prior austenite ad also in martensite contours. The dissolution of these precipitates can form rich regions in Ni while continuing aging which were more favorable regions for reversion of austenite. Up to a certain amount of reversed austenite can result in an improvement of toughness. Increasing the amount of austenite however toughness decreases.
According to Hou et al. ${ }^{14}$, maraging steels forged and solution annealed at temperatures of $750,800,850,900,950$ and $1000{ }^{\circ} \mathrm{C}$ for 1 hour and then aged at $500{ }^{\circ} \mathrm{C}$ for 2 hours have their mechanical properties reduced with increasing temperature. They also observed that there was a significant reduction in the impact energy of $60 \mathrm{~J}$ to $10 \mathrm{~J}$ with respect to temperatures of $750{ }^{\circ} \mathrm{C}$ and $1000{ }^{\circ} \mathrm{C}$ respectively. This fact could be confirmed by analyzing the specimen after the impact test, which indicated that the increase in specimen of solubilization temperature caused a brittle fracture in the specimen. Unlike what was observed by Houet al, in this study the samples treated at $1000^{\circ} \mathrm{C}$ and aged at $480{ }^{\circ} \mathrm{C}$ presented the best results in terms of impact energy, reaching about $30.5 \mathrm{~J}$ and a ductile fracture. For the other samples treated at other temperatures, it was found that despite the low impact energy, all presented ductile fracture after the Charpy test.

The hardness of the samples in turn, even with the variation of temperature and consequently the grain size, showed similar values even for one with the highest impact energy.

As noted by Shaet et al. ${ }^{15}$, after aging treatments you can check the formation of small light particles that stand out on the microstructure of the material. These authors assumed that these particles are reverted austenite, which in turn contribute to increased toughness. Many particles like these were observed in the samples that were aged.

\section{Conclusions}

With the results obtained from the present study in which we aimed to evaluate the influence of solution annealing and aging maraging 300 , it was concluded that:

a- The solution annealing at high temperatures contributed to increase grain size of the microstructure;

b- The samples treated at $1000^{\circ} \mathrm{C}$ and aged at $480^{\circ} \mathrm{C}$ showed the best results, particularly with regard to increasing the toughness of the material;

c- The values for the hardness of the material present a small variation with annealing temperature treatment.

\section{Acknowledgements}

The authors thank the coordination of higher level of personal development - CAPES for promoting the research work.

\section{References}

1. Yang K, Qu WS, Kong FY, Su GY. Effects of solution treatment temperature on grain growth and mechanical properties of high strength $18 \%$ Ni cobalt free maraging steel. Materials Science and Technology. 2003;19(1):117-124.

2. Pardal JM, Tavares SSM, Fonseca MPC, Abreu HFG, Silva JJM. Study of the austenite quantification by X-ray diffraction in the $18 \mathrm{Ni}-\mathrm{Co}-\mathrm{Mo}-\mathrm{Ti}$ maraging 300 steel. Journal of Materials Science. 2006;41(8):2301-2307. 
3. Sinha PP, Sreekumar K, Natarajan A, Nagarajan KV. Grain growth in 18Ni 1800 MPa maraging steel. Journal of Materials Science. 1991;26(15):4155-4159.

4. Johnson WC, Stein DF. A study of grain boundary segregants in thermally embrittled maraging steel. Metallurgical Transactions. 1974;5(3):549-554.

5. Ashbrook RW, Marder AR. The effect of initial carbide morphology and abnormal grain growth in decarburized low carbon steel. Metallurgical Transactions A. 1985;16(5):897-906.

6. Burke JE, Turnbull D. Recrystallization and grain growth. Progress in Metal Physics. 1952;3: 220, IN11, 245, IN13, 267, IN15, 275-244-IN12-266-IN14-274-292.

7. Magnée A, Drapier JM, Dumont J, Coutsouradis D, Habraken L. Cobalt-containing high-strength steels. Brussels: Centre d'Information du Cobalt; 1974

8. Pardal JM, Tavares SSM, Terra VF, Silva MR, Santos DR. Modeling of precipitation hardening during the aging and overaging of $18 \mathrm{Ni}-\mathrm{Co}-\mathrm{Mo}-\mathrm{Ti}$ maraging 300 steel. Journal of Alloys and Compounds. 2005;393(1-2):109-113.

9. Decker RF. Source book on maraging steels: A comprehensive collection of outstanding articles from the periodical and reference literature. Materials Park: ASM International; 1979.
10. Rack HJ. Age hardening-grain size relationships in $18 \mathrm{Ni}$ maraging steels. Materials Science and Engineering. 1978;34(3):263-270.

11. Liu K, Shan YY, Yang ZY, Liang JX, Lu L, Yang K. Effect of heat treatment on prior grain size and mechanical property of a maraging stainless steel. Journal of Materials Science \& Technology. 2006;22(6):769-774.

12. Il'ina VP, Troitskaya VA. Effect of low-temperature quenching on the microstructure and capacity for corrosion cracking steel 03Kh11N10M2T-VD. Metal Science and Heat Treatment. 2000;42(2):53-56.

13. He Y, Liu K, Yang K. Effect of solution temperature on fracture toughness and microstructure of ultra-purified $18 \mathrm{Ni}(350)$ maraging steel. Acta Metallurgica Sinica. 2003;39:381-386.

14. Hou H, Qi L, Zhao YH. Effect of austenitizing temperature on the mechanical properties of high-strength maraging steel. Materials Science and Engineering: A. 2013;587:209-212.

15. Sha W, Ye A, Malinov S, Wilson EA. Microstructure and mechanical properties of low nickel maraging steel. Materials Science and Engineering: A. 2012;536:129-135. 